\title{
ARTICLE OPEN \\ Influence of young cement water on the corrosion of the International Simple Glass
}

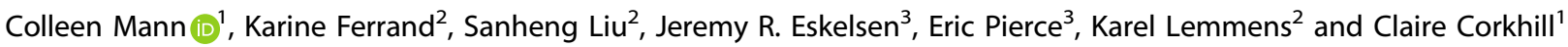

Understanding the corrosion of nuclear waste glass is critical to predicting its safe disposal within a geological facility. The corrosion mechanisms and kinetics of the International Simple Glass, a simplified version of high-level nuclear waste glass, was shown to be significantly influenced by a high $\mathrm{pH}$ cement solution representative of disposal conditions. We provide the first microscopic characterisation of the porous, Zr-rich aluminoalkali-silica gel corrosion layer that was observed. $\mathrm{Ca}$, $\mathrm{Na}$ and $\mathrm{K}$ from the cement solution were incorporated into the corrosion layer to charge compensate $\mathrm{Si}, \mathrm{Al}$ and $\mathrm{Zr}$ species; the incorporation of $\mathrm{Al}$ was postulated to result in precipitation of an aluminosilicate-rich gel with large voids, facilitating rapid transport of species through the gel layer and significantly enhancing the corrosion rate. Precipitation of Al-containing zeolite and phyllosilicate phases was also observed, indicating that cementitious solutions may promote the detrimental 'rate resumption' stage of glass corrosion.

npj Materials Degradation (2019)3:5; doi:10.1038/s41529-018-0059-9

\section{INTRODUCTION}

It is the consensus of the regulatory agencies of a number of countries that vitrified nuclear waste should be disposed of within a deep geological disposal facility where it can safely undergo radioactive decay, isolated from the environment and future populations. Cement will be ubiquitous in all geological disposal facilities, being used to line underground vaults, in seals and plugs, as buffer material and in general construction. It is expected to play a key role in the Belgian and UK disposal concepts for high- and intermediate-level vitrified waste, respectively. ${ }^{1-3}$ The interaction of cementitious pore water with vitrified waste is a key issue, since the generation of a hyperalkaline plume could accelerate glass dissolution mechanisms, thereby enhancing radionuclide release from the vitrified waste.

Generally, glass undergoes several parallel mechanisms during dissolution: ionic exchange, hydrolysis of the silica network, in situ condensation of silica species, and precipitation of secondary crystalline phases, primarily phyllosilicates and zeolites. ${ }^{4-10}$ Depending on the reaction progress and the leaching conditions, one or more of the previous mechanisms control the overall dissolution rate. Under hyperalkaline conditions, the solubility of sparingly soluble elements present in the glass (e.g. Si, $\mathrm{Al}$ and $\mathrm{Zr}$ ) increases. ${ }^{11-14}$ When combined with high concentrations of $\mathrm{Ca}$ from cement leachate, the formation of the silica gel is disrupted and instead, a Ca-silica containing gel layer, interspersed with dense $\mathrm{Si}-\mathrm{Zr}$ layers, is formed that restricts fluid transport; decreasing the glass dissolution rate. ${ }^{14-19}$ Additionally, the alteration phases formed (e.g. calcium silicate hydrates (C-S-H), calcium aluminosilicate hydrates (C-A-S-H) and zeolites) differ from those typically observed under near-neutral solution conditions. ${ }^{11-19}$ Some studies indicate that, in the short term, these phases form a protective layer on the surface of the glass, further reducing the dissolution. ${ }^{15,16}$ In contrast, other studies have shown that, in the longer-term, the formation of $\mathrm{C}-\mathrm{S}-\mathrm{H}$ and zeolite phases leads to a resumption of glass alteration since the fast precipitation of $\mathrm{C}-(\mathrm{A})-\mathrm{S}-\mathrm{H}$ consumes silica (and $\mathrm{Al}$ ) from solution, causing undersaturation and destabilisation of the passivating gel layer. ${ }^{20,21}$ Such a glass alteration resumption is highly undesirable for long-term storage of vitrified nuclear waste. ${ }^{22}$ It is postulated that such longer-term resumption may be related to the continual leaching of $\mathrm{Ca}$ during the degradation of cement by infiltrating groundwater. ${ }^{23}$

While numerous studies have been performed to understand the dissolution mechanisms of glass in the presence of simple hyperalkaline media, for example, in $\mathrm{Ca}(\mathrm{OH})_{2}, \mathrm{NaOH}$ or $\mathrm{KOH}$ solutions, few studies have investigated the role of cementitious leachates, which contain $\mathrm{Na}, \mathrm{K}$ and $\mathrm{Ca}$, in addition to a range of other elements. ${ }^{23-25} \mathrm{Na}$ and $\mathrm{K}$ alkalis exist in cement primarily as alkali sulphate salts, which are readily soluble and leach easily from cement into water upon initial contact, forming a 'cement leachate'. After an initial release of alkalis, the cement hydrate phase, portlandite $\left[\mathrm{Ca}(\mathrm{OH})_{2}\right]$, is dissolved and the cement leachate becomes Ca-rich and is buffered to $\mathrm{pH} \sim 12.6$. With time, and continued dissolution of cement clinker and hydrate minerals, the composition of the cement leachate will change and will be controlled by $\mathrm{C}-\mathrm{S}-\mathrm{H}$ dissolution; the $\mathrm{pH}$ will decrease to $\sim 11.8$ (at ambient temperature), the concentration of alkali elements will decrease, and the concentrations of $\mathrm{Ca}, \mathrm{Al}$ and $\mathrm{Si}$ will increase significantly. ${ }^{26}$ The influence of these complex solutions on the processes that control dissolution of vitrified waste is not yet represented in models of glass dissolution because the required data are not available.

The objective of this study was to gain a deeper understanding of glass dissolution in cement leachate solution. Therefore, we conducted a 2-year leaching study with young cement leachate assumed to be in equilibrium with portlandite (referred to as YCWCa) on the dissolution of International Simple Glass (ISG, a simplified version of the French SON68 nuclear waste simulant

\footnotetext{
${ }^{1}$ NucleUS Immobilisation Science Laboratory, Department of Materials Science and Engineering, University of Sheffield, Sheffield, UK; ${ }^{2}$ SCK.CEN, Mol, Belgium and ${ }^{3}$ Oak Ridge National Laboratory, Oak Ridge, TN, USA

Correspondence: Claire Corkhill (c.corkhill@sheffield.ac.uk)
}

Received: 22 February 2018 Accepted: 4 November 2018

Published online: 22 January 2019 
glass) ${ }^{27}$ powders and monoliths at 30 and $70^{\circ} \mathrm{C}$. The results, which include analyses of aqueous solutions, geochemical modelling and detailed microscopy characterisation of reacted glass, suggest that under certain experimental conditions, the altered layers formed in high $\mathrm{pH}$, alkaline solutions significantly impact solute transport to and from the pristine glass interface, ultimately influencing the glass dissolution rate.

\section{RESULTS}

\section{Dissolution rate determination}

The YCWCa solution maintained a high $\mathrm{pH}$ throughout the duration of the experiments; at $30^{\circ} \mathrm{C}$ it was constant and remained at the value of the blank solution $(\mathrm{pH}(\mathrm{RT}) 13.5)$, while at $70^{\circ} \mathrm{C}$ a decline to $\mathrm{pH}(\mathrm{RT}) 12$ was observed (Supplementary Material Fig. S1).

The elemental release of $\mathrm{Si}, \mathrm{B}, \mathrm{Ca}$ and $\mathrm{Al}$ with time at 30 and $70^{\circ} \mathrm{C}$ is shown in Fig. 1 ; the corresponding normalised mass loss $\left(\mathrm{NL}_{\mathrm{i}}\right)$ for $\mathrm{Si}, \mathrm{B}, \mathrm{Al}$ and $\mathrm{Zr}$ is given in Fig. S2. Dissolution rates were obtained from linear regression of $\mathrm{NL}_{B}$ data (Fig. S2a and $\mathrm{S} 2 \mathrm{e}$ ). At $30^{\circ} \mathrm{C}$, the concentration of $\mathrm{B}$ continuously increased throughout the experiment and a dissolution rate of $(4.00 \pm 0.15) \times 10^{-3} \mathrm{~g}$ $\mathrm{m}^{-2}$ day $^{-1}$ was measured (Fig. S2a). In contrast, at $70^{\circ} \mathrm{C}$, after a rapid increase in $\mathrm{B}$ concentration at 32 days, there was little further release of this element (Fig. 1). The dissolution rate during the initial rapid increase was $(4.42 \pm 0.40) \times 10^{-2} \mathrm{~g} \mathrm{~m}^{-2}$ day $^{-1}$ and in the plateau was $(8.84 \pm 3.99) \times 10^{-4} \mathrm{~g} \mathrm{~m}^{-2}$ day $^{-1}$ (Fig. S2e). At both temperatures, the release of $\mathrm{Al}$ to solution was initially high, but was subsequently observed to decrease, indicative of the incorporation of $\mathrm{Al}$ into alteration layers or secondary phases. The release of Si to solution was significantly different at 30 and $70{ }^{\circ} \mathrm{C}$ (Fig. 1); at the lower temperature, there was an almost linear increase in the concentration of $\mathrm{Si}$, reaching a final concentration of $\sim 100 \mathrm{mmol} \mathrm{L}^{-1}$ after 622 days (Fig. 1), while at the higher temperature, the concentration was $\sim 220 \mathrm{mmol} \mathrm{L}^{-1}$ after only 32 days, at which point a slight decrease was observed. Regardless of the temperature, the concentration of $\mathrm{Ca}$, which was initially present in the solution and the glass, decreased at the beginning of the experiments to levels below $0.05 \mathrm{mmol} \mathrm{L}^{-1}$ (values of $0.044 \pm 0.001$ and $0.047 \pm 0.003 \mathrm{mmol} \mathrm{L}^{-1}$ were measured at 30 and $70{ }^{\circ} \mathrm{C}$, respectively). The removal of $\mathrm{Ca}$ from solution over the initial 32 days is indicative of the formation of a Ca-containing alteration layer.

The concentration of $\mathrm{Zr}$ remained lower than $400 \mu \mathrm{mol} \mathrm{L}^{-1}$ at $30^{\circ} \mathrm{C}$ and $150 \mu \mathrm{mol} \mathrm{L}^{-1}$ at $70^{\circ} \mathrm{C}$, indicating that it may also have been incorporated in the glass alteration layer (Fig. S2d and h), and the concentration of $K$, a major constituent of the YCWCa, was observed to decrease at both temperatures; the initial concentration was $367 \mathrm{mmol} \mathrm{L}^{-1}$ and after 622 days at 30 and $70^{\circ} \mathrm{C}$, the concentration fell to $\sim 300$ and $\sim 175 \mathrm{mmol} \mathrm{L}^{-1}$, respectively, once again indicating incorporation into the glass alteration layer.

\section{Geochemical modelling}

Two different models were applied to simulate the experimental dissolution results: (1) an affinity-based model where congruent dissolution is driven by the undersaturation of the solution with respect to silica; and (2) a diffusion model that describes alteration-layer limited diffusion, i.e. when the alteration products (gel and precipitates) cover the glass surface and limit solute transport, decreasing the dissolution rate.

The affinity model is given in Eq. (1), where $d m / d t$ is the rate of the glass dissolution in $\mathrm{gday}^{-1}, A_{0}\left(\mathrm{~m}^{2}\right)$ is the initial glass surface area, $m(\mathrm{~g})$ and $m_{0}(\mathrm{~g})$ are the current and initial mass of glass, $r_{0}$ is a fitted linear rate in $\mathrm{g} \mathrm{m}^{-2}$ day $^{-1}$ (note that $r_{0}$ is different from the initial rate, defined as the glass dissolution rate in sufficiently dilute solution; rather, it is a combined fitting parameter with both $\mathrm{pH}$ and solution cation effects included), [Si] is the silica concentration in the solution in $\mathrm{mol} \mathrm{L}^{-1}$ and $\left[\mathrm{Si}_{\mathrm{sat}}\right]$ is the saturation concentration of silica with respect to a silica-containing phase in $\mathrm{mol} \mathrm{L}^{-1}$.

$\frac{d m}{d t}=-A_{0}\left(\frac{m}{m_{0}}\right)^{\frac{2}{3}} r_{0}\left(1-\frac{[S i]}{\left[S i_{s a t}\right]}\right)$

The alteration-layer limited diffusion model is given in Eq. (2) and is accompanied by Eqs. (3) and (4), which describe the evolution of elemental concentration under diffusion-limited dissolution. In these equations, $C_{i}\left(\mathrm{~mol} \mathrm{~L}^{-1}\right)$ is the concentration of an element $i, A_{0}\left(\mathrm{~m}^{2}\right)$ is the initial surface area of the glass, $V(\mathrm{~L})$ is the solution volume, $x_{i}$ (dimensionless) is the mass fraction of element $i$ in the glass, $\rho\left(\mathrm{g} \mathrm{m}^{-3}\right)$ is the density of the glass, $D_{i}\left(\mathrm{~m}^{2}\right.$ day $\left.{ }^{-1}\right)$ and $M_{i}\left(\mathrm{~g} \mathrm{~mol}^{-1}\right)$ are the diffusion coefficient and the atomic weight of an element, and $t(\mathrm{~d})$ is the time.

$\frac{d m}{d t}=-A_{0} \rho \sqrt{\frac{D_{i}}{\pi t}}$

The amount of glass dissolved, $\Delta m$ in $\mathrm{g}$, after time $t$ is obtained by integrating Eq. (2) on both sides:

$\Delta m=m_{0}-m=2 A_{0} \rho \sqrt{\frac{D_{i} t}{\pi}}$

Assuming congruent dissolution, the concentration of an element, $i$, in the solution is calculated as:

$C_{i}=\frac{2 A_{0} \rho}{V M_{i}} x_{i} \sqrt{\frac{D_{i} t}{\pi}}$

Eqs. (2)-(4) are similar to the analytical solution to Fick's second law for diffusion into semi-infinite media. Such equations have also been used to describe solid state inter-diffusion of alkali ions and protons in the glass during dissolution at relatively low $\mathrm{pH}$, assuming no glass surface retreat and zero alkali surface concentration. ${ }^{28}$ In applying Eqs. (2) and (4) to model glass dissolution in hyper-alkaline conditions, it is necessary to assume that the glass surface is not retreating. As will be shown later, the surface layer of the altered glass was enriched in $\mathrm{K}^{+}$and depleted in $\mathrm{Na}^{+}$. The replacement of smaller $\mathrm{Na}^{+}$ions with larger $\mathrm{K}^{+}$ions at the glass surface is expected to prevent the collapse of the glass network and the retreat of the glass surface, although further investigation is required to confirm this. In the proposed model, it is assumed that a dissolution front progressed proportionately to the square root of time into the pristine glass and that the region behind the dissolution front was completely dissolved into solution (assuming congruent dissolution). It is further assumed that precipitation (or re-condensation in the case of amorphous silica) of secondary phases back onto the glass surface compensated for the retreat of the glass surface, leading to the formation of an alteration layer with a thickness that increased with the square root of time. Thus the size of the original glass sample did not change with time, only the size of the inner unreacted core (the glass) decreases (i.e. isovolumetric substitution). This is the same as pseudomorphic replacement processes that commonly occur in geochemical reactions. ${ }^{29,30}$ Additionally, it was assumed that when the solution became over-saturated with respect to certain secondary phases, these phases precipitated from solution.

Eqs. (1) and (2) were implemented into the PHREEQC geochemical code as a kinetic reaction, however, to ensure a good fit to the experimental data, it was necessary to impose specific equilibrium controls on the reaction. Firstly, to ensure a good fit for Ca concentrations, the solution was considered to be in equilibrium with $\mathrm{C}-\mathrm{S}-\mathrm{H}$ (in an ideal solid solution with end member $\mathrm{Ca} / \mathrm{Si}$ ratios of 0.8 and 1.6). Secondly, phillipsite-K, a Kcontaining zeolite, was assumed to be in equilibrium with the solution; ${ }^{31,32}$ this ensured a good fit for the Al solution data and helped to improve fits for K. To accurately model the Si data, it was also necessary to assume equilibrium with a K-bearing alkali-silica 

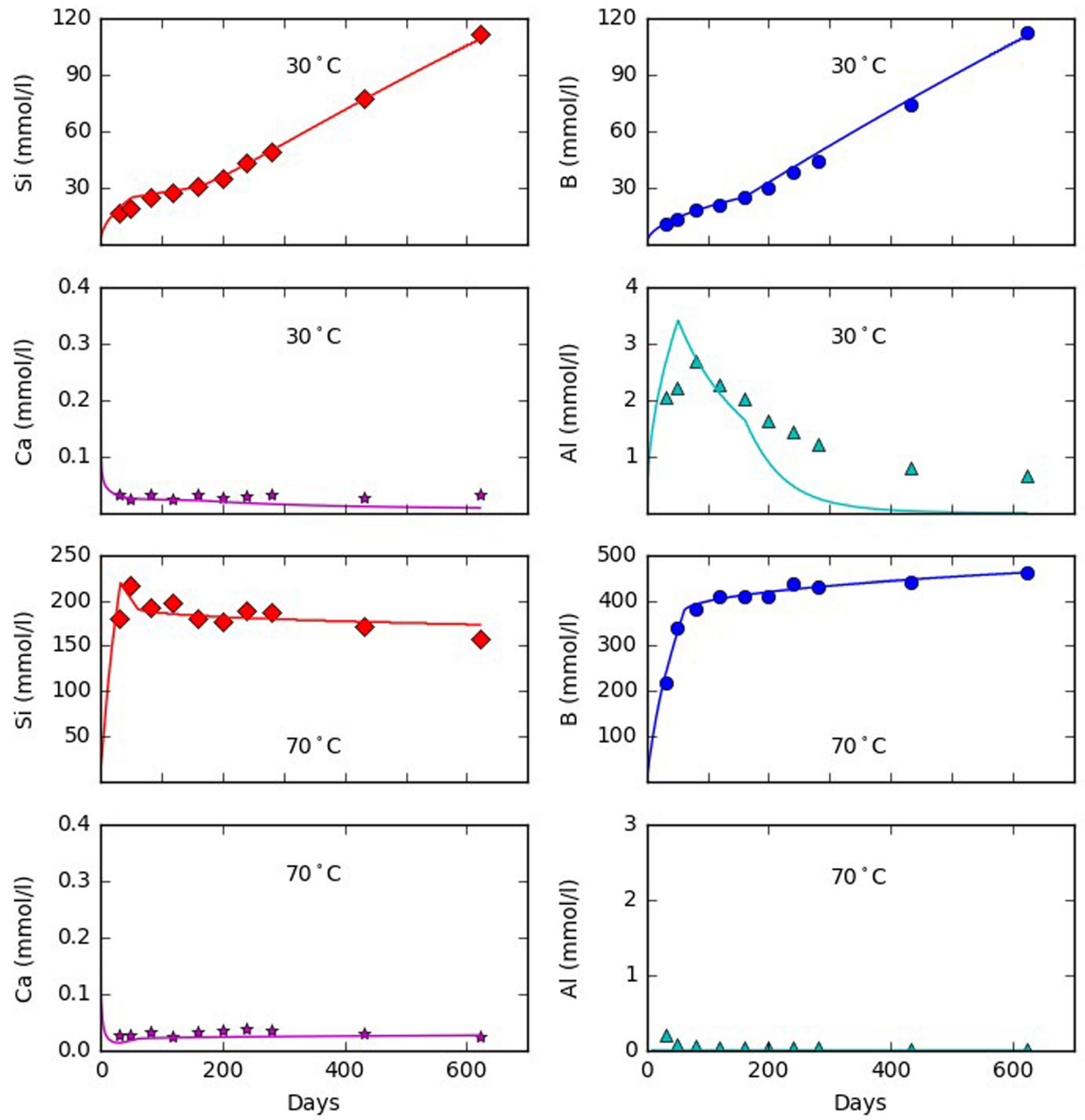

Fig. 1 Measured (points) and modelled (lines) concentrations of Si, B, Ca and Al vs time in YCWCa at 30 and $70^{\circ} \mathrm{C}$. Data points shown are the average of duplicate measurements

gel. The results of geochemical modelling, through the application of these equations and phases, are shown in Fig. 1.

At $30^{\circ} \mathrm{C}$, particularly prior to 160 days of dissolution, the alteration-layer diffusion limited equation (Eq. (2)) described the glass dissolution well. This is evidenced by a parabolic increase of $\mathrm{B}$ and $\mathrm{Si}$ concentration with time before 160 days, as was previously observed for SON68 subject to leaching under the same conditions. ${ }^{32}$ After more than 160 days of dissolution, the $B$ and $\mathrm{Si}$ concentrations were observed to increase linearly with time. It was only possible to model this behaviour by the application of Eq. (1), however, because there was still a rapid increase in $\mathrm{Si}$ concentration at the end of the experiment (i.e. no Si-saturation) it was necessary to omit the Si saturation term. This suggests that the glass dissolved uninhibitedly after 160 days and that the diffusion step was no longer rate limiting; this indicates a change in the properties of the alteration layer after this time.
Using Eq. (4), the calculated diffusion coefficients based on B and Si release data at $30^{\circ} \mathrm{C}$ were $(2.78 \pm 0.78) \times 10^{-21}$ and $(8.49 \pm$ $2.37) \times 10^{-22} \mathrm{~m}^{2} \mathrm{~s}^{-1}$, respectively. This is somewhat higher than that measured by Gin et al., ${ }^{33}$ who calculated a diffusion coefficient of hydrous species through the passivating layer of ISG, at $\mathrm{pH} 9$ and $90^{\circ} \mathrm{C}$, between 209 and 875 days of dissolution, to be $1.3 \times 10^{-23} \mathrm{~m}^{2} \mathrm{~s}^{-1}$. This difference may be due to the different time scale investigated here (160 days) and in the study of Gin et al., ${ }^{33}$ i.e. diffusion may be faster at shorter durations of dissolution time, however, other possible reasons will be discussed further in the following sections.

For the experiment at $70^{\circ} \mathrm{C}$, Si concentrations were initially high and then decreased throughout the experiment, indicating that $\mathrm{Si}$ containing secondary phase precipitation rate exceeded the glass dissolution rate. The affinity term in Eq. (1) (with silica saturation included) gave a reasonable fit for $\mathrm{Al}$ and $\mathrm{Ca}$ concentrations. For $\mathrm{B}$ 

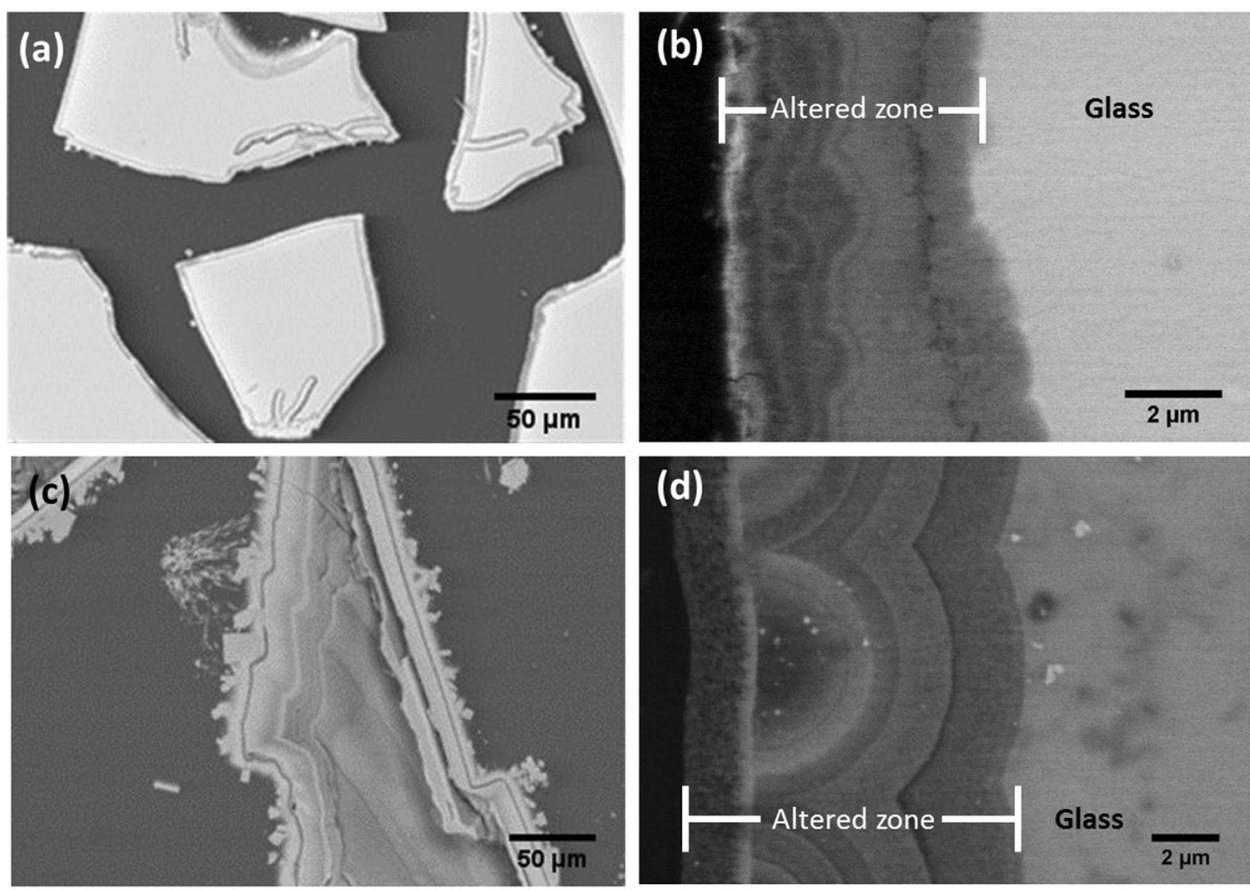

Fig. 2 Alteration layers formed on the surface of ISG after 622 days for powders and 721 days for the monoliths; $30^{\circ} \mathrm{C}$ : $\mathbf{a}$ powder; and $\mathbf{b}$ monolith; $70^{\circ} \mathrm{C}$ : c powder; and $\mathbf{d}$ monolith

at $70^{\circ} \mathrm{C}$, after the initial rapid increase associated with the degradation of the glass network, the release rate decreased after about 60 days, but did not reach a constant value. The decrease was possibly due to the presence of precipitated phases on the glass surface that limit the transport of solution to and from the glass interface inhibiting further dissolution. From 60 days of dissolution onwards, according to Eq. (4), the diffusion coefficient based on $B$ release data was $1.95 \times 10^{-20} \mathrm{~m}^{2} \mathrm{~s}^{-1}$. This is greater than the reported residual $B$ diffusion coefficients for ISG in $\mathrm{Si}$ saturated solutions, which suggests that alteration layer formed in YCWCa solution had a higher porosity ${ }^{34}$ or that the reaction may not be diffusion limited.

\section{Alteration layer and secondary phase analysis}

At $30^{\circ} \mathrm{C}$, an amorphous alteration layer, 2-10 $\mu \mathrm{m}$ in thickness, was observed on the glass powders, as shown in Fig. 2a (associated EDX is provided in Fig. S3), and on the monolithic specimen from the same experiment, shown in Fig. $2 \mathrm{~b}$. This layer comprised three regions; a dense band on the outer edge of the layer (i.e. in contact with solution), a more porous region close to the surface of the glass and, in between, a finely banded region, where the bands were 'scalloped' in morphology, with a convex boundary towards the surface of the glass, as previously observed by Dohmen et al. ${ }^{35}$ The composition of each of these portions of the layer appeared to be the same, comprising $\mathrm{Si}, \mathrm{Al}, \mathrm{Na}, \mathrm{K}, \mathrm{Ca}$ and $\mathrm{Zr}$, with an $\mathrm{Al} / \mathrm{Si}$ ratio of $0.22 \pm 0.04$ (compared to an $\mathrm{Al} / \mathrm{Si}$ ratio of 0.12 in the bulk glass and of 1.20 in the blank YCWCa solution). The Ca/ Si ratio in the gel layer was $\sim 0.25$, which is significantly lower than expected for $\mathrm{C}-\mathrm{S}-\mathrm{H}$ (typical end members have a $\mathrm{Ca} / \mathrm{Si}$ ratio of 0.6 and 1.2). The average altered layer thickness, as measured on monolith samples, was $5.7 \pm 0.2 \mu \mathrm{m}$ (Fig. 2b) and the altered glass fraction (AGF) was $11.3 \pm 0.7 \%$.

Dissolution at $70^{\circ} \mathrm{C}$ also resulted in the formation of a gel layer with multiple bands, as shown in Fig. 2c, d (and Figs. S4-S6). The average thickness of the altered layer was $15.6 \pm 0.9 \mu \mathrm{m}$ and the AGF was $41.2 \pm 0.1 \%$, similar to that observed for SON68 dissolved in $\mathrm{KOH}$ at $90^{\circ} \mathrm{C}$ for 365 days. ${ }^{11}$ The bands were composed of $\mathrm{Si}, \mathrm{Al}$, $\mathrm{Na}, \mathrm{K}, \mathrm{Ca}$ and $\mathrm{Zr}$ with an $\mathrm{Al} / \mathrm{Si}$ ratio in the range of $0.04 \pm 0.003$ to
$0.19 \pm 0.01$ (the lower end of this range is considerably lower than the bulk glass).

Framboidal and radiating acicular crystallites, ranging in size from 5 to $60 \mu \mathrm{m}$ in length, were observed to form around the outer edge of glass grains reacted at $70^{\circ} \mathrm{C}$ (Fig. 2C), but were absent in experiments at $30^{\circ} \mathrm{C}$. EDX analysis of the crystalline phases at $70^{\circ} \mathrm{C}$ (Fig. S5 and S6) indicated two distinct compositions; needle-like crystallites were enriched in $\mathrm{K}, \mathrm{Si}$ and $\mathrm{Ca}$ (Supplementary Figure 6, e.g. EDX spots 45-48), while crystallites with a rhombohedral morphology were composed of K, Si and Al (Fig. S6, e.g. EDX spots 12-15). EDX results were in good agreement with XRD analysis (Fig. 3), where diffraction peaks could be indexed to: the phyllosilicate, rhodesite $\left[\left(\mathrm{Ca}_{1} \mathrm{Na}_{2}\right.\right.$, $\left.\mathrm{K}_{2}\right)_{8} \mathrm{Si}_{16} \mathrm{O}_{40} \cdot 11 \mathrm{H}_{2} \mathrm{O}$ ] (PDF 00-022-1253) ${ }^{36}$ (corresponding to needle-like crystallites in Figs. S5 and S6); the zeolite, phillipsite$\mathrm{K}\left[\mathrm{Na}_{4} \mathrm{KAI}_{5} \mathrm{Si}_{11} \mathrm{O}_{32} \cdot 10 \mathrm{H}_{2} \mathrm{O}\right.$ ] (PDF 01-073-1419) ${ }^{37}$ (corresponding the rhombohedral crystallites in Figs. S5 and $\mathrm{S6}$ ); and silicon oxide $\left[\mathrm{SiO}_{2}\right]$ (PDF 01-082-1573). ${ }^{38}$ None of the crystallites formed were found to contain $\mathrm{Zr}$, indicating that this element was exclusively partitioned into the gel layer, in agreement with previous studies. $^{8,16}$

Focused ion beam (FIB)-sections prepared from monoliths withdrawn from YCWCa solution after 721 days of dissolution at $70{ }^{\circ} \mathrm{C}$ were analysed by TEM, as shown in Figs. 4 and 5 . The scalloped altered layers identified by SEM were also observed at this scale; the band closest to the glass surface was Band 1 (Fig. 4). Each of the layers was composed of $\mathrm{Ca}, \mathrm{Zr}, \mathrm{Al}, \mathrm{K}, \mathrm{O}$ and $\mathrm{Si}$, and there was no change in relative concentration of each element within each band (see Fig. S7), therefore the observed differences in intensity in the dark field (DF) and secondary electron (SE) images (Fig. 4) can be attributed to variations in the void volume (i.e. porosity) in each band.

Higher magnification TEM images (Fig. 5) confirmed the existence of microstructural variation between the bands; each of the layers exhibited a 'speckled' pattern of apparently different porosity. This type of porosity may be attributed to the presence of individual silica-containing spheres, ${ }^{39}$ and the corresponding interstitial space between these spheres; this has been previously 
(a)

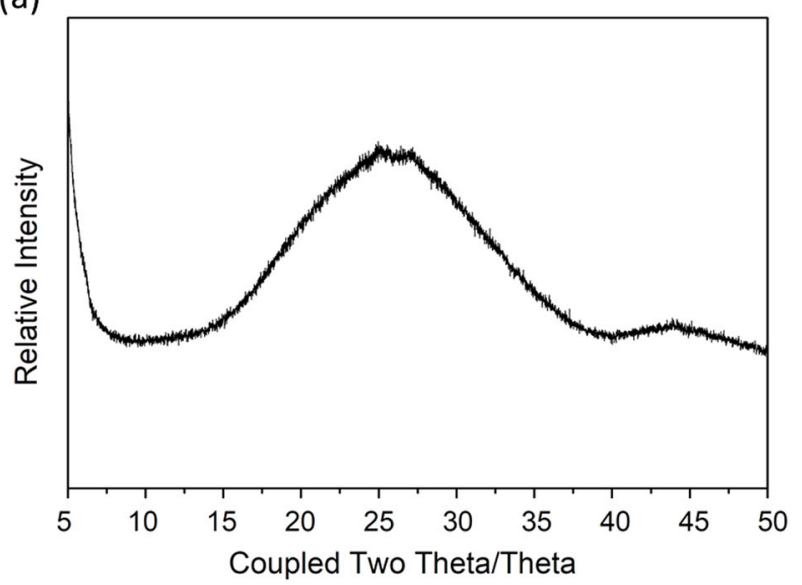

(b)

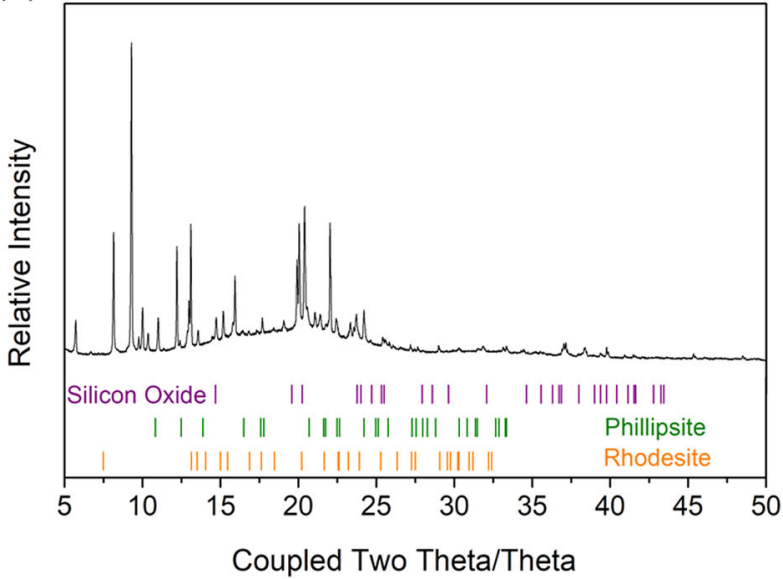

Fig. 3 Diffraction patterns for monolith samples exposed to YCWCa for 622 days at $\mathbf{a} 30^{\circ} \mathrm{C}$ and $\mathbf{b ~} 70^{\circ} \mathrm{C}$. Phases indexed at $70^{\circ} \mathrm{C}$ were: rhodesite $\left[\left(\mathrm{Ca}_{1} \mathrm{Na}_{2}, \mathrm{~K}_{2}\right)_{8} \mathrm{Si}_{16} \mathrm{O}_{40} \cdot 11 \mathrm{H}_{2} \mathrm{O}\right.$, PDF 00-022-1253]; ${ }^{36}$ phillipsite$\mathrm{K}\left[\mathrm{Na}_{4} \mathrm{KAI}_{5} \mathrm{Si}_{11} \mathrm{O}_{32} \cdot 10 \mathrm{H}_{2} \mathrm{O}\right.$, PDF 01-073-1419]; ${ }^{37}$ and silicon oxide $\left[\mathrm{SiO}_{2}, \mathrm{PDF}\right.$ 01-082-1573] ${ }^{38}$

observed in the post-nucleation ripening of silica gels. ${ }^{35,39}$ It is well understood that the combined influence of high $\mathrm{pH}$ and the presence of cationic species can influence polymerisation of $\mathrm{Si}-\mathrm{OH}$ gels; at high $\mathrm{pH}$ values, the negatively charged silica species, $\mathrm{Si}$ $(\mathrm{OH})^{3-}$ and $\mathrm{Si}(\mathrm{OH})_{2}{ }^{2-}$, experience repulsion due to their negative charge, which prevents aggregation and gives rise to large interstitial pores between poorly aggregated silica. However, the presence of other cationic species can compensate for this charge, allowing aggregation and gel formation. The data shown in Fig. 4 indicate that the cations $\mathrm{Ca}, \mathrm{K}, \mathrm{Na}$ and the anions $\mathrm{Si}, \mathrm{Al}$ and $\mathrm{Zr}$ contributed to the formation of an alumino-alkali-silica gel at the surface of ISG reacted in YCWCa solution. Since the layers were not found to change significantly in composition (at the scale of the techniques applied, Fig. S7), small variations in $\mathrm{pH}$, which would influence the silica aggregation process and the resulting size of the silica spheres, may be the cause of the varied porosity.

Image analysis, using grey scale thresholding and assuming a constant composition, gave an average pore radius across the whole layer, ranging from 7 to $15 \mathrm{~nm}$. This is somewhat higher than observed in similar glasses at lower $\mathrm{pH}$, for example, the R7T7 glass was reported to have an altered layer porosity of $\sim 2 \mathrm{~nm}$ in static leaching conditions at $\mathrm{pH} 7-9,{ }^{40}$ pores of $5 \mathrm{~nm}$ were measured for SON68 at pH $9,{ }^{41}$ and pores of $\sim 1 \mu \mathrm{m}$ were observed in LAWB45 glass. ${ }^{42}$ However, our results are in excellent agreement with Ferrand et al., ${ }^{23}$ who measured a pore radius size of $10 \mathrm{~nm}$ for SON68 reacted in cement water. Diffraction patterns obtained using selective area electron diffraction (SAED; Fig. 5) revealed each of the bands to be amorphous.

\section{DISCUSSION}

The dissolution of ISG in YCWCa can be described by two key stages: (1) the formation of a porous, Zr-containing alkali aluminosilica gel, during which time rapid dissolution occurs; and (2) the precipitation of a crust of zeolite and phyllosilicate crystalline phases. The formation of the latter was concurrent with the slowing of dissolution rate at $70^{\circ} \mathrm{C}$ only. In both stages, the high $\mathrm{pH}$ and the composition of the cement leachate solution was found to exert a significant influence on the dissolution behaviour, as described below.

As discussed previously, polymerisation of silicic acid by condensation reactions results in nucleation of a porous gel that becomes more dense as reorganisation and Ostwald ripening takes place. ${ }^{5,35,43}$ The TEM data presented in this study, which showed a speckled, porous morphology, provides compelling evidence that an alkali alumino-silica gel is formed at the surface of ISG leached in cementitious solution, where the high $\mathrm{pH}$ of the leachate solution causes repulsion among the negatively charged silica particles, negatively influencing the polymerisation of silica anions, and forming large interstitial pores between silica gel particles. Our results, in agreement with those for SON68 at high $\mathrm{pH}^{23}$ and also for ISG, where the void fraction of the gel was found to increase as a function of increasing $\mathrm{pH}^{44}$ indicate that the pore radius of the gel at the $\mathrm{pH}$ of the cement leachate investigated $(\mathrm{pH}(\mathrm{RT}) 13.5)$ is approximately twice the size of that in gels formed in circum-neutral $\mathrm{pH}$ solutions. Consequently, the calculated B diffusion coefficients in the present study were several orders of magnitude higher than those of ISG in $\mathrm{Si}$ saturated solutions, ${ }^{33}$ demonstrating the dramatic influence of YCWCa solution on ISG dissolution.

The chemical composition of the solution clearly had a significant influence on the formation of the alteration layers. The uptake of $\mathrm{K}, \mathrm{Ca}, \mathrm{Na}, \mathrm{Zr}$ and $\mathrm{Al}$ into the silica gel indicates that the alteration layer was in equilibrium with the cement solution and is evidence that solution cations were readily transported into the open pore network of the gel layer. Alkali/alkali-earth cation incorporation into the gel layer is likely driven by charge compensation for anionic species in the silica gel. For example, recent studies by Collin et al. ${ }^{45}$ showed that $\mathrm{Ca}$ is the preferred charge balancing cation for $\left[\mathrm{AlO}_{4}\right]^{-}$units in the gel of ISG at pH 7 .

The presence of these cations has an apparently detrimental effect on the glass alteration (e.g. higher B diffusion coefficient than observed for the same glass at circumneutral $\mathrm{pH}) .{ }^{33}$ Previous studies have shown that in the presence of the alkali species, $\mathrm{Na}$ and $\mathrm{K}$, the rate of quartz dissolution was significantly enhanced. ${ }^{46}$ This was attributed to the fact that these elements have a higher frequency of solvent exchange (the rate at which primary solvation waters of a cation exchange with the surrounding aqueous environment) than the other alkali/alkali earths, which increases the frequency of silica hydrolysis and thus the rate of dissolution. ${ }^{46}$ It follows that in the presence of $\mathrm{Na}$ and $\mathrm{K}$, under the high $\mathrm{pH}$ conditions experienced by the ISG in this investigation, the rate-limiting step of dissolution was the breakage of $\mathrm{Si}-\mathrm{O}-\mathrm{Si}$ bonds. This is in agreement with previous studies of the UK nuclear waste simulant, MW25, at high $\mathrm{pH}$, where investigation of dissolution rate parameters at $\mathrm{pH}(\mathrm{RT}) \mathrm{8}, 10$ and 12 showed incongruent leaching of $\mathrm{Si}$ when compared to $\mathrm{Na}$ and $\mathrm{B} .{ }^{47}$ Since Ca has a much lower frequency of solvent exchange, it is less likely to enhance the dissolution rate of glass than $\mathrm{K}$ or $\mathrm{Na}$, but nevertheless, due to its divalent charge, it is a more efficient charge balancing cation than the alkali elements, thus is incorporated readily into the gel, as seen in numerous previous studies. $^{11-19,23,25}$ 

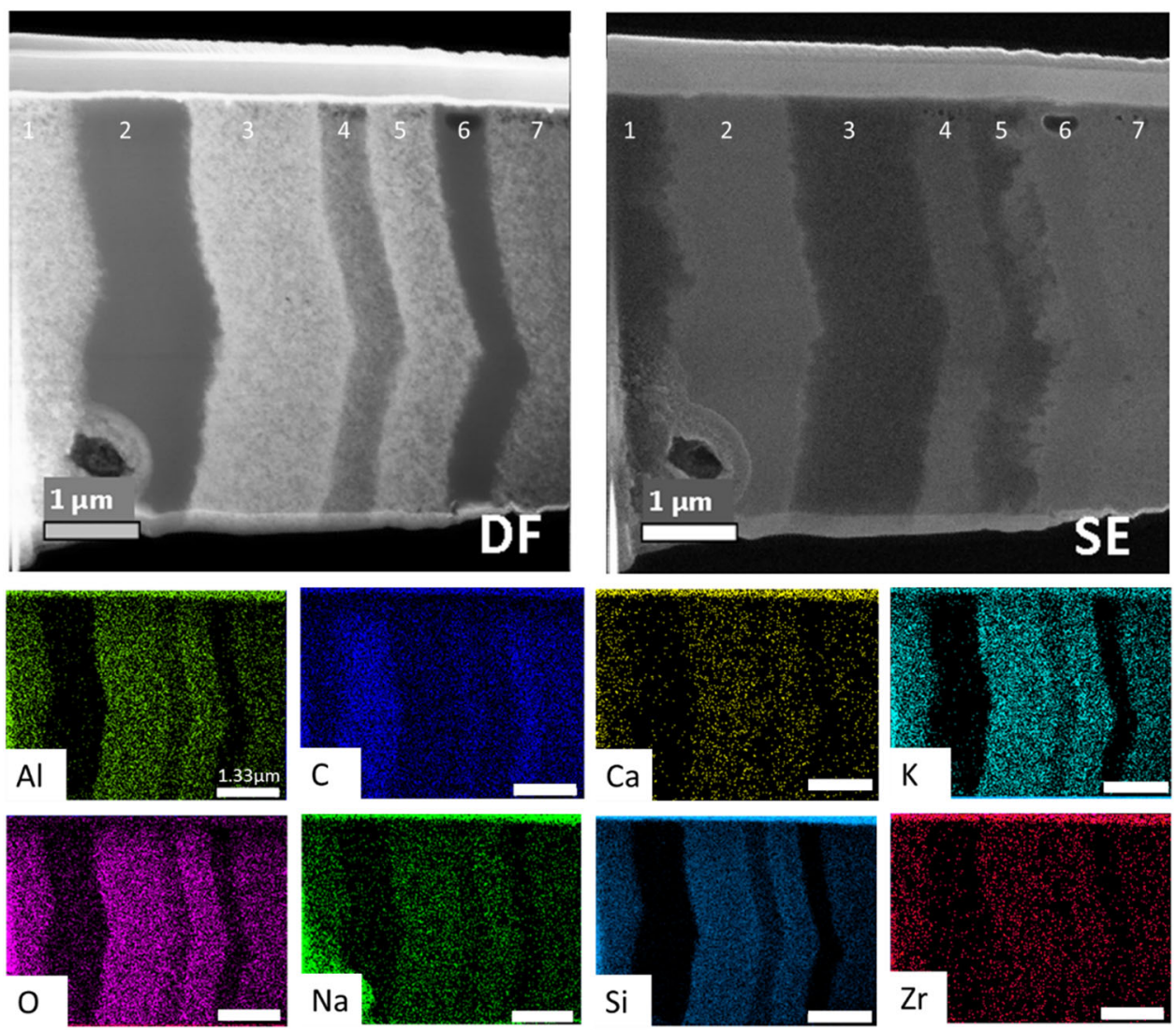

Fig. 4 Scanning transmission electron microscopy (STEM), dark-field scanning TEM (DF STEM), secondary electron STEM images and energydispersive spectroscopy images of a focused ion beam (FIB) section removed from a monolith of ISG leached for 721 days at $70{ }^{\circ} \mathrm{C}$. Individual STEM-EDX images are provided for Al, C, Ca, K, O, Na, Si and Zr. The middle section of the alteration layer is shown; Band 1 is located closest to (but not in contact with) the bulk glass, and Band 7 is towards (but not in contact with) the solution. Bands 2 and 6 are filled with epoxy resin

At $30^{\circ} \mathrm{C}$, the corrosion behaviour appeared to change at 160 days (see B and Si profiles, Fig. 1). This occurred after Al had reached a maximum concentration and started to be consumed from solution; at this time the dissolution rate could no longer be modelled with a diffusion term, but rather by an affinity-type model with the affinity term (i.e. saturation of $\mathrm{Si}$ ) removed. This can be interpreted as if the system is very far from the theoretical dissolution-suppressing silica saturation concentration. One possible explanation for this behaviour could be as follows: the incorporation of $\mathrm{Na}, \mathrm{K}$ and $\mathrm{Ca}$ in the gel (to charge compensate negatively charged $\mathrm{Si}, \mathrm{Al}$ and $\mathrm{Zr}$ species) gave rise to a diffusioncontrolled dissolution rate until the gel layer became positively charged (i.e. it contained an excess of $\mathrm{K}, \mathrm{Na}$ and $\mathrm{Ca}$ required to charge balance $\left[\mathrm{AlO}_{4}\right]^{-},\left[\mathrm{ZrO}_{6}\right]^{2-}, \mathrm{Si}(\mathrm{OH})^{3-}$ and $\mathrm{Si}(\mathrm{OH})_{2}{ }^{2-}$ units). At this time (160 days), dissolved $\left[\mathrm{AlO}_{4}\right]^{-}$species in solution were attracted to the gel layer, but since there was no further $\mathrm{Ca}^{2+}$ in solution to provide charge balance to these anions (Fig. 1), the less efficient charge balancing cations, $\mathrm{K}^{+}$and $\mathrm{Na}^{+}$, were used. In the presence of $\mathrm{K}$ and $\mathrm{Na}$ at high $\mathrm{pH}$, the aluminosilicate species, $(\mathrm{OH})_{3} \mathrm{AlOSiO}_{n}(\mathrm{OH})_{(3-n)}^{(n+1)}$, where $n=1-3$, has been shown to precipitate, not as a nano-sized gel but instead as much larger granules. ${ }^{48}$ It is possible that the change in dissolution rate observed at $30^{\circ} \mathrm{C}$ and 160 days when Al was incorporated into the gel, was the result of the precipitation of poorly charge-balanced aluminosilicate species, which, due to their granular nature, gave rise to the presence of large voids (or a more open pore network) in the gel layer, allowing for rapid dissolution. This hypothesis requires experimental validation, but does not seem implausible since it has been previously shown that $\left[\mathrm{ZrO}_{6}\right]^{2-}$ may become incorporated in silica gel formed on ISG when leached at high $\mathrm{pH}^{14,16}$ inhibiting restructuring of the gel layer, enhancing porosity and thus increasing dissolution. ${ }^{49,50}$

From the results presented here, it is not possible to discern the individual effects of (1) high $\mathrm{pH}$ and (2) cation incorporation in the silica gel layer, on the development of porosity and the enhancement of dissolution rate, but it is evident that both play a significant role in maintaining an open pore network through which solution and glass species can be transported. Although the inclusion of a K-bearing alkali-silica gel improved the geochemical model fit, it is clear that the other cations present also participated in gel layer formation; further studies should be directed at elucidating the relative roles of the alkali and alkaliearth cations on gel layer formation and glass dissolution.

\section{Secondary phase precipitation}

At $70^{\circ} \mathrm{C}$, the extent of dissolution of ISG was greater than at $30^{\circ} \mathrm{C}$ (e.g. the AGF was $11 \pm 1 \%$ and $41 \pm 1 \%$ for 30 and $70^{\circ} \mathrm{C}$, respectively) and the release of elements could be modelled with an affinity-based model, accounting for the precipitation of the zeolite phase, phillipsite-K, and also C-S-H (Fig. 1). In contrast with previous studies of ISG dissolution at high $\mathrm{pH}^{14,16}$ and our own geochemical modelling, there was no evidence for $\mathrm{C}-\mathrm{S}-\mathrm{H}$ precipitates. Their absence is due to the low $\mathrm{Ca}$ concentration in solution and the propensity for Ca incorporation into silica gel. ${ }^{46}$ Zeolite and phyllosilicate phases were precipitated on the outside of the alkali alumino-silica gel, indicating that gel formation 

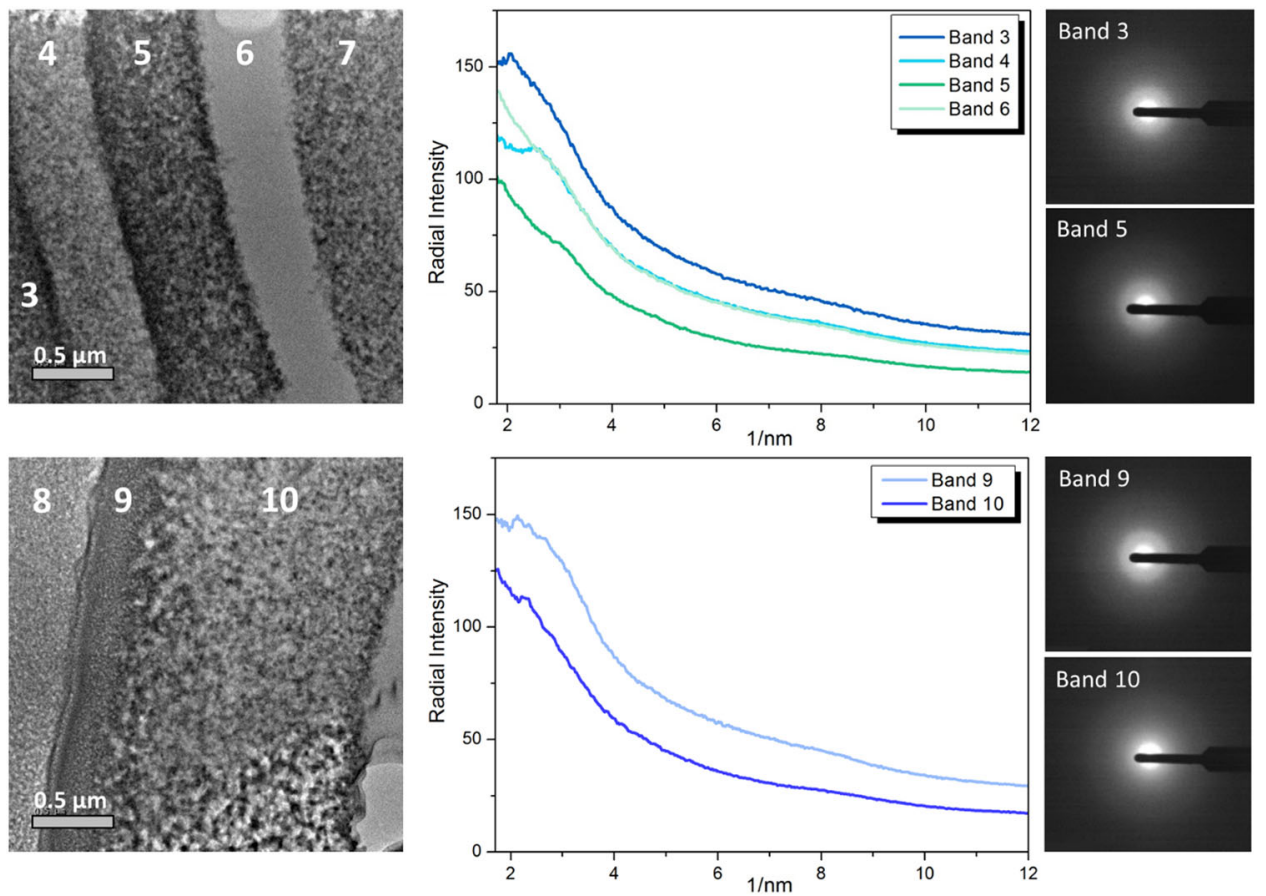

Fig. 5 Transmission electron microscope images of ISG reacted in YCWCa for 721 days at $70^{\circ} \mathrm{C}$, showing the variation in the porosity of the different bands (numbered 3 to 10) in the alteration layer, with the corresponding Selective Area Electron Diffraction (SAED) patterns

preceded precipitation of secondary phases. Previous studies of ISG leached in water show no secondary precipitates, ${ }^{14}$ thus highlighting the significant role of solution species, particularly the alkali and alkali earth elements in cement water, and $\mathrm{pH}$ in the alteration of glasses.

Comparing the Al dissolution data for 30 and $70^{\circ} \mathrm{C}$, it is clear that at $30^{\circ} \mathrm{C}$, where no zeolites were observed to form, significant quantities of $\mathrm{Al}$ remained in solution (albeit decreasing towards the end of the experiment), while at $70^{\circ} \mathrm{C}$, almost all of the Al had been consumed from solution. Despite this, the $\mathrm{Al} / \mathrm{Si}$ ratio of the gel layer at $70^{\circ} \mathrm{C}$ was significantly lower than at $30^{\circ} \mathrm{C}(0.04$ compared with 0.22 , respectively; the $\mathrm{Al} / \mathrm{Si}$ ratio in the bulk glass was 0.12). As such, it may be concluded that the zeolite and phyllosilicate phases formed at $70^{\circ} \mathrm{C}$ were nucleated from the gel layer (i.e. the alkali/alkaline-earth aluminosilicate gel formed at $30^{\circ} \mathrm{C}$, may be a non-crystalline pre-cursor for the zeolite phases observed at $70^{\circ} \mathrm{C}$ ), as proposed by previous studies..$^{51,52}$ This is in agreement with the hypothesis presented above; if weakly bound to the gel layer as large granules of aluminosilicate, Al may thus provide a ready source for the formation of secondary phases. The other alkali/alkali-earths within the gel layer were found to be zeolite- and phyllosilicate-forming elements, however since they were present in high concentration in solution (particularly $\mathrm{Na}$ and $\mathrm{K})$, the source of these elements could be the solution or the gel.

The consumption of $\mathrm{Al}$ from the gel to form zeolites has previously been related to the onset of glass alteration resumption (or Stage III dissolution behaviour), ${ }^{51,52}$ as has a reduction in the $\mathrm{pH}$ of the solution, also seen in the present study at $70^{\circ} \mathrm{C}$ (Fig. S1). The onset of enhanced dissolution at $70^{\circ} \mathrm{C}$ occurred as the $\mathrm{Al}$ concentration reduced; this behaviour is in accordance with previously reported rate resumption behaviour for SON68, which entered this stage of dissolution after 100 days. ${ }^{24}$ It is important to note that the influence of cation species in the gel layer on rate resumption is not well understood; from the data presented in the current study it can be postulated that the presence of these elements do not appear to stabilise it entirely.
Table 1. Target composition of synthetic young cement water with added calcium (YCWCa), in $\mathrm{mmol} \mathrm{L}^{-1}$, after Ferrand et al. ${ }^{23}$

\begin{tabular}{|llllllll}
\hline & \multicolumn{7}{c}{ Element concentration $\left(\mathrm{mmol} \mathrm{L}^{-1}\right)$} \\
\cline { 2 - 8 } & $\mathrm{Ca}$ & $\mathrm{Na}$ & $\mathrm{K}$ & $\mathrm{Al}$ & $\mathrm{Si}$ & $\mathrm{S}$ & $\mathrm{C}$ \\
\hline YCWCa & 0.70 & 141.00 & 367.00 & 0.06 & 0.05 & 2.00 & 0.30 \\
\hline
\end{tabular}

\section{METHODS}

Glass materials

ISG was produced by MoSci Corporation (Rolla, MO, USA-Lot number: L12012601-M12042403) with the following nominal composition in mol\%: $\mathrm{SiO}_{2}, 60.2 \% ; \mathrm{B}_{2} \mathrm{O}_{3}, 16.0 \% ; \mathrm{Na}_{2} \mathrm{O}, 12.7 \% ; \mathrm{Al}_{2} \mathrm{O}_{3}, 3.8 \% ; \mathrm{CaO}, 5.7 \%$; and $\mathrm{ZrO}_{2}$, $1.7 \%$. A diamond blade slow saw was used to cut monoliths, $14 \times 14 \times$ $2 \mathrm{~mm}$ in size, which were finished to P4000 using SiC paper. Glass fragments were milled and sieved to obtain a powder with a size fraction between 125 and $250 \mu \mathrm{m}$. The specific surface area measured by BET [Micromeritics ASAP 2020] using $\mathrm{Kr}$ adsorbent gas was $0.046 \pm 0.0001 \mathrm{~m}^{2}$ $\mathrm{g}^{-1}$.

\section{Dissolution methodology}

Static tests were performed at SCK.CEN at 30 and $70{ }^{\circ} \mathrm{C}$ in synthetic young cement water with added calcium (solution was assumed to be in equilibrium with portlandite, giving a Ca concentration of $16 \mathrm{mg} \mathrm{L}^{-1}$ ) with a composition as reported by Ferrand et al., shown in Table $1 .{ }^{23}$ The solution, referred to as YCWCa, was prepared in an inert atmosphere glove box to prevent carbonation, at room temperature, and had a $\mathrm{pH}$ measured at $23 \pm 1{ }^{\circ} \mathrm{C}(\mathrm{pH}(\mathrm{RT}))$ of $13.5 \pm 0.2$. Experiments were conducted using $9 \mathrm{~g}$ of glass powder and two monoliths, in contact with $50 \mathrm{~mL}$ of solution that had been equilibrated at either 30 or $70^{\circ} \mathrm{C}$; the surface area to volume ratio (SA/V) was $8280 \mathrm{~m}^{-1}$ (not considering the glass monoliths, which alter the SA/V to $\left.8302 \mathrm{~m}^{-1}\right)$. Tests were performed in duplicate using a bespoke reactor (shown in Fig. S8), where the monoliths were located on a Teflon ${ }^{\circledast}$ holder above glass powder settled on the bottom of the vessel; the powder and monoliths were not in contact. Blank tests without glass were also performed. Solutions were manually stirred for a few hours before the 
removal of $1 \mathrm{~mL}$ aliquots at regular time points. The aliquots were acidified prior to analysis $\left(\mathrm{HNO}_{3}\right)$ and diluted with $2 \mathrm{~mL}$ ultra-high quality water and the chemical composition determined by ICP-AES or MS ( $X$ series II Thermo Fisher). One monolith was removed from solution after 200 days and the other at 721 days. The normalised mass loss $\mathrm{NL}_{\mathrm{i}}\left(\mathrm{g} \mathrm{m}^{-2}\right)$ was calculated according to Eq. (5):

$$
N L_{i}=\frac{\left(C_{i} \cdot V \cdot F_{i}\right)}{f_{i} \cdot S A}=\frac{\left(m_{i} \cdot F_{i}\right)}{\left(f_{i} \cdot \frac{S A}{V}\right)}
$$

where $C_{i}$ is the concentration of element $i$ in the aliquot of solution $\left(\mathrm{mg} \mathrm{L}^{-1}\right), V$ is the total volume of solution $\left(\mathrm{m}^{3}\right), F_{i}$ is the factor to convert the atomic weight of element $i$ to the molecular weight of the oxide containing element $i, f_{i}$ is the weight $\%$ of the oxide containing element $i$ in the pristine glass, $\mathrm{SA}$ is the total surface area of the exposed glass $\left(\mathrm{m}^{2}\right)$ and $m_{i}$ is the mass of element $i(\mathrm{~g})$. The $\mathrm{NL}_{i}$ values are further corrected by taking into account the volume decrease due to periodic sampling of solution aliquots and evaporation and the amount of glass components (e.g. B, Si, etc.) that were discarded with the previous sampling, by adding the cumulative amounts of $\mathrm{B}, \mathrm{Si}$, etc. in the discarded sample to the amount still present in the leachate at a given time point. The boron equivalent thickness-the maximum possible thickness of the alteration layer, assuming congruent dissolution-was calculated using the normalised mass loss of boron at the end of the experiment.

\section{Solution and alteration layer analysis}

Glass samples were analysed by X-ray diffraction to determine the crystalline phases present at the end of the dissolution experiment. The analysis was performed on altered glass powder using Philips X'Pert Pro System (SCK.CEN) with the following settings: two theta range $5-60^{\circ}$, step size $0.02^{\circ} 2 \theta, 30 \mathrm{~s}$ per step, $\mathrm{Cu} \mathrm{Ka}$ radiation and $X^{\prime}$ Celerator detector. Monoliths were examined using a Bruker D2 Phaser X-ray diffractometer (University of Sheffield) in theta two theta mode with $\mathrm{Cu}$ Ka radiation, using a Ni filter and a LynxEye position sensitive detector. Diffraction data were acquired with an incident beam slit of $0.6 \mathrm{~mm}$ and a knife edge $(1 \mathrm{~mm})$ to eliminate stray scatter. The data acquisition parameters were the following: start $2 \theta=5^{\circ}$, end $2 \theta=70^{\circ}$, step size $=0.02^{\circ}$, count time per step $=2.2 \mathrm{~s}$, effective total scan time $=6 \mathrm{~h}$, no sample rotation. The X-ray tube settings were $30 \mathrm{kV}$ and $10 \mathrm{~mA}$. The resulting patterns were evaluated with the aid of X'Pert High Score Plus software and PDF 2 mineral database.

The glass alteration layers were examined using a field emission scanning electron microscope (SEM) (powders were analysed on a JEOL JSM 6610 and monoliths on a Hitachi S-4800). Energy dispersive X-ray spectroscopy (EDX) was utilised to determine the chemical composition of altered layers and the total layer thickness was determined by line measurements around glass grains and in the cross-sectional images of the monolith ( 440 measurements per sample). Thin sections across the alteration layers of the monoliths were prepared using a Hitachi NB5000 dual focused ion beam scanning electron microscope (FIB-SEM). Monolith thin sections were examined using a cold field emission Hitachi HF-3300 high-resolution transmission electron microscope with an accelerating voltage of $300 \mathrm{keV}$ at Oak Ridge National Laboratory, which has the capability to generate simultaneous secondary electron and STEM images. EDX was performed using a Bruker XFlash silicon drift detector (SDD) attached to the HF3300 TEM/STEM/SEM for elemental mapping of the thin FIB section. This was utilised to determine the composition and structure of the altered layers.

Image J was used to measure the average pore size diameter. The TEM images were processed with a fast Fourier transform (FFT) bandpass filter to exclude features larger than 100 pixels and smaller than 3 pixels; the aim of this step was to achieve an even brightness across the image and to reduce noise to ensure better results when thresholding. Black and white inversion highlighted pores in white for size analysis against the image scale.

\section{Geochemical modelling}

The solution data were modelled according to Eqs. (1)-(4), detailed in the main text, by implementation in Phreeqc using the Thermochimie database at SCK.CEN.

\section{DATA AVAILABILITY}

The data that support the findings of this study are available from the corresponding author upon reasonable request.

\section{ACKNOWLEDGEMENTS}

The UK research team are grateful to the Engineering and Physical Science Research Council for funding under grant awards EP/N017374/1 and EP/G037140/1. This research was performed, in part, at the MIDAS Facility, at the University of Sheffield, which was established with support from the Department of Energy and Climate Change. This project was co-financed by ONDRAF/NIRAS, the Belgian Agency for the Management of Radioactive Waste and Fissile Materials, as part of its program on the geological disposal of high-level and intermediate-level long-lived radioactive waste. The authors gratefully acknowledge the technical support from Ben Gielen. The portions of the research conducted at Oak Ridge National Laboratory (ORNL) were supported by the US Department of Energy's Office of Environmental Management (EM) Tank Waste Management program. ORNL is operated by UT-Battelle, LLC for the US DOE under Contract No. DE-AC05-00OR22725.

\section{AUTHOR CONTRIBUTIONS}

All authors provided substantial contributions to conception of the research performed, or the acquisition, analysis or interpretation of the data; they drafted or revised the manuscript; approved the final version and; are accountable for the accuracy and integrity of the data and its interpretation.

\section{ADDITIONAL INFORMATION}

Supplementary information accompanies the paper on the npj Materials Degradation website (https://doi.org/10.1038/s41529-018-0059-9).

Competing interests: The authors declare no competing interests.

Publisher's note: Springer Nature remains neutral with regard to jurisdictional claims in published maps and institutional affiliations.

\section{REFERENCES}

1. Bel, J. J. P., Wickham, S. M. \& Gens, R. M. F. Development of the supercontainer design for deep geological disposal of high-level heat emitting radioactive waste in Belgium. Mater. Res. Soc. Symp. Proc. 932, 23-32 (2006).

2. Geological disposal: steps towards implementation. Nuclear Decommissioning Authority Report. NDA/RWMD/013 (2010).

3. Vasconcelos, R. G. W. et al. Characterisation of a high pH cement backfill for the geological disposal of nuclear waste: the Nirex Reference Vault Backfill. Appl. Geochem. 89, 180-189 (2018).

4. Frugier, P. et al. SON68 nuclear glass dissolution kinetics: current state of knowledge and basis of the new GRAAL model. J. Nucl. Mater. 380, 8-21 (2008).

5. Geisler, T. et al. The mechanism of borosilicate glass corrosion revisited. Geochim. Cosmochim. Acta 158, 112-129 (2015).

6. Vienna, J. D., Gin, S., Ryan, J. V. \& Inagaki, Y. Current understanding and remaining challenges in modeling long-term degradation of borosilicate nuclear waste glasses. Int. J. Appl. Glass Sci. 4, 283-294 (2013).

7. Gin, S. et al. The controversial role of inter-diffusion in glass alteration. Chem. Geol. 440, 115-123 (2016).

8. Gin, S. \& Mestre, J. P. SON68 nuclear glass alteration kinetics between $\mathrm{pH} 7$ and pH 11.5. J. Nucl. Mater. 295, 83-96 (2001).

9. Ferrand, K., Abdelous, A. \& Grambow, B. Water diffusion in the simulated French nuclear waste glass SON68 contacting silica rich solutions: experimental and modelling. J. Nucl. Mater. 355, 54-67 (2006).

10. Van Iseghem, P. et al. Chemical durability of high level waste glass in repository environment: main conclusions and remaining uncertainties from the GLASTAB and GLAMOR projects. Mater. Res. Soc. Symp. Proc. 932, 293-304 (2006).

11. Ribet, S. \& Gin, S. Role of neoformed phases on the mechanisms controlling the resumption of SON68 glass alteration in alkaline media. J. Nucl. Mater. 324, 152-164 (2004).

12. Utton, C. A. et al. Dissolution of vitrified wastes in a high-pH calcium-rich solution. J. Nucl. Mater. 435, 112-122 (2013).

13. Mercado-Depierre, S., Angeli, F., Frizon, F. \& Gin, S. Antagonist effects of calcium on borosilicate glass alteration. J. Nucl. Mater. 441, 402-410 (2013).

14. Gin, S. et al. The fate of silicon during glass corrosion under alkaline conditions: a mechanistic and kinetic study with the International Simple Glass. Geochim. Cosmochim. Acta 151, 68-85 (2015). 
15. Corkhill, C. L., Cassingham, N., Heath, P. G. \& Hyatt, N. C. Dissolution of UK high level waste glass under simulated hyperalkaline conditions of a co-located geological disposal facility. Int. J. Appl. Glass Sci. 4, 341-356 (2013).

16. Backhouse, D. J. A Study of the Dissolution of Nuclear Waste Glasses in Highlyalkaline Conditions. PhD thesis, University of Sheffield, UK (2016).

17. Chave, T., Frugier, P., Gin, S. \& Ayral, A. Glass-water interphase reactivity with calcium-rich solutions. Geochim. Cosmochim. Acta 75, 4125-4139 (2011).

18. Utton, C. A. et al. Chemical durability of vitrified wasteforms: effects of $\mathrm{pH}$ and solution composition. Miner. Mag. 76, 2919-2930 (2012).

19. Utton, C. A., Hand, R. J., Hyatt, N. C., Swanton, S. W. \& Williams, S. J. Formation of alteration products during dissolution of vitrified ILW in a high-pH calcium-rich solution. J. Nucl. Mater. 442, 33-45 (2013).

20. Rajmohan, N., Frugier \& Gin, S. Composition effects on synthetic glass alteration mechanisms: Part 1. Experiments. Chem. Geol. 279, 106-119 (2010).

21. Gin, S., Beaudoux, X., Angeli, F., Jegou, C. \& Godon, N. Effect of composition on the short-term and long-term dissolution rates of ten borosilicate glasses of increasing complexity from 3 to 30 oxides. J. Non-Cryst. Solids 358, 2559-2570 (2012).

22. Fournier, M., Gin, S. \& Frugier, P. Resumption of nuclear glass alteration: state of the art. J. Nucl. Mater. 448, 348-363 (2014).

23. Ferrand, K., Liu, S. \& Lemmens, K. The interaction between nuclear waste glass and Ordinary Portland cement. Int. J. Appl. Glass Sci. 4, 328-340 (2013).

24. Liu, S., Ferrand, K. \& Lemmens, K. Transport- and surface reaction-controlled SON68 glass dissolution at $30^{\circ} \mathrm{C}$ and $70^{\circ} \mathrm{C}$ and $\mathrm{pH}=13.7$. Appl. Geochem. 61, 302-311 (2015).

25. Andriambololona, Z., Godon, N. \& Vernaz, E. R7T7 glass alteration in the presence of mortar-effect of the cement grade. Mater. Res. Soc. Symp. Conf. Proc. 257, 151-158 (1992)

26. Berner, U. R. Evolution of pore water chemistry during degradation of cement in a radioactive waste repository environment. Proc. Waste Manage. 12, 201-219 (1992).

27. Gin, S. et al. An international initiative on long-term behaviour of high-level nuclear waste glass. Mater. Today 16, 243-248 (2013).

28. Lasaga, A. C. Kinetic Theory in the Earth Sciences (Princeton University Press, Princeton, 1990)

29. Putnis, A. Mineral replacement reactions: from macroscopic observations to microscopic mechanisms. Miner. Mag. 66, 689-708 (2002).

30. Putnis, A. \& Putnis, C. V. The mechanism of re-equilibration of solids in the presence of a fluid phase. J. Solid State Chem. 180, 1783-1786 (2007).

31. Mann, C., Le Hoh, T., Thorpe, C. L. \& Corkhill, C. L. Dissolution of glass in cementitious solutions: an analogue study for vitrified waste disposal. MRS Adv. $\mathbf{3}$, 1147-1154 (2018).

32. Liu, S., Ferrand, K. \& Lemmens, K. Transport- and surface reaction-controlled SON68 glass dissolution at $30^{\circ} \mathrm{C}$ and $70^{\circ} \mathrm{C}$ and $\mathrm{pH}=13.7$. Appl. Geochem. 61, 302-311 (2015).

33. Gin, S. et al. Atom-probe tomography, TEM and ToF-SIMS study of borosilicate glass alteration rim: a multiscale approach to investigating rate-limiting mechanisms. Geochim. Cosmochim. Acta 202, 57-76 (2017).

34. Chave, T., Frugier, P., Ayral, A. \& Gin, S. Solid state diffusion during nuclear glass residual alteration in solution. J. Nucl. Mater. 362, 466-473 (2007).

35. Dohmen, L. et al. Pattern formation in silicate glass corrosion zones. Int. J. Appl. Glass Sci. 4, 357-370 (2013).

36. Sheppard, R. \& Gude, A. Rhodesite from Trinity Country, California. Am. Mineral. 54, 251-256 (1969)

37. Steinfink, H. The crystal structure of the zeolite, phillipsite. Acta Crystallogr. 15, 644-651 (1962)
38. Boisen, M. B., Gibbs, G. V. \& Bukowinski, M. S. T. Framework silica structures generated using simulated annealing with a potential energy function based on an $\mathrm{H}_{6} \mathrm{Si}_{2} \mathrm{O}_{7}$ molecule. Phys. Chem. Miner. 21, 269-284 (1994).

39. Iler, R. K. The Chemistry of Silica: Solubility, Polymerisation, Colloid and Surface Properties, and Biochemistry (John Wiley \& Sons, New York, 1979).

40. Deurelle, O., Spalla, O., Barboux, P. \& Lambard, J. Growth and ripening of porous layers in water altered glasses. J. Non-Cryst. Solids 261, 237-251 (2000).

41. Rebiscoul, D. et al. Morphological evolution of alteration layers formed during nuclear glass alteration: new evidence of a gel as a diffusive barrier. J. Nucl. Mater. 326, 9-18 (2004).

42. Hopf, J. et al. Toward an understanding of surface layer formation, growth, and transformation at the glass-fluid interface. Geochim. Cosmochim. Acta 229, 65-84 (2018).

43. Ostwald, W. Besprechung der arbeit von Liesegangs "A-Linien". Phys. Chem. 69, 27-39 (1897).

44. Kaspar, T. C., Reiser, J. T., Ryan, J. V. \& Wall, N. A. Non-destructive characterisation of corroded glass surfaces by spectroscopic ellipsometry. J. Non-Cryst. Solids $\mathbf{4 8 1}$, 260-266 (2018)

45. Collin, M., Fournier, M., Charpentier, T., Moskura, M. \& Gin, S. Impact of alkali on the passivation of silicate glass. npj Mater. Degrad. 2, 16 (2008).

46. Dove, P. \& Nix, C. J. The influence of alkaline earth cations, magnesium, calcium, and barium on the dissolution kinetics of quartz. Geochim. Cosmochim. Acta 61 3329-3340 (1997).

47. Cassingham, N. et al. The initial dissolution rates of simulated UK Magoz-ThORP blend nuclear waste glass as a function of $\mathrm{pH}$, temperature and waste loading Miner. Mag. 79, 1529-1542 (2015).

48. North, M. R., Fleischer, A. \& Swaddle, T. W. Precipitation from alkaline aqueous aluminosilicate solutions. Can. J. Chem. 79, 75-79 (2001).

49. Cailleteau, C. et al. Insight into silicate-glass corrosion mechanisms. Nat. Mater. 7, 978-983 (2008).

50. Cailleteau, C., Devereux, F., Spalla, O., Angeli, F. \& Gin, S. Why do certain glasses with a high dissolution rate undergo a low degree of corrosion? J. Phys. Chem. $C$ 115, 5846-5855 (2011).

51. Mercado-Depierre, S., Fournier, M., Gin, S. \& Angeli, F. Influence of zeolite precipitation on borosilicate glass alteration under hyperalkaline conditions. J. Nucl. Mater. 491, 67-82 (2017).

52. Fournier, M., Gin, S., Frugier, P. \& Mercado-Depierre, S. Contribution of zeoliteseeded experiments to the understanding of resumption of glass alteration. $n p j$ Mater. Degrad. 1, 1-13 (2017).

(i) Open Access This article is licensed under a Creative Commons Attribution 4.0 International License, which permits use, sharing, adaptation, distribution and reproduction in any medium or format, as long as you give appropriate credit to the original author(s) and the source, provide a link to the Creative Commons license, and indicate if changes were made. The images or other third party material in this article are included in the article's Creative Commons license, unless indicated otherwise in a credit line to the material. If material is not included in the article's Creative Commons license and your intended use is not permitted by statutory regulation or exceeds the permitted use, you will need to obtain permission directly from the copyright holder. To view a copy of this license, visit http://creativecommons. org/licenses/by/4.0/.

(c) The Author(s) 2019 